Ärztliche Erfahrung beschränkt sich nicht auf medizinisches Fachwissen.

Sie entsteht auch aus den mehr oder minder alltäglichen, heiter, ärgerlich oder nachdenklich stimmenden Erlebnissen mit Patienten, Kollegen und Mitarbeitern. Senden Sie uns Ihre Geschichte an: cornelius.heyer@springer.com.

\title{
Krampfadern? Operieren!!
}

_ „Ich muss so schnell wie möglich meine Krampfadern operieren lassen“, eröffnete mir neulich eine junge Dame mit schreckgeweiteten Augen, ,aber ich möchte das nicht! Ich habe solche Angst!“ Tatsächlich zogen einige Varizen über ihre Unterschenkel, aber dank Stützstrümpfen war weder eine Entzündung noch ein Ödem zu sehen. „Sie müssen das doch nicht", tröstete ich sie. „Wenn Sie mit den Strümpfen klarkommen, geht es ohne OP.“

Sie schien an meinem Verstand zu zweifeln: „Ich war doch im Krankenhaus, und der Arzt hat mir gesagt, dass ich ohne Operation in spätestens einem Jahr eine Lungenembolie erleiden und sterben würde“, flüsterte sie. Mir stockte der Atem. Die Arme hatte sich mit der Frage nach den Krampfadern ungeschickterweise an den Notdienst gewandt, der sie gleich zu den Chirurgen weiterleitete. Hier war sie auf einen jungen Kollegen gestoßen, dem das Skalpell wohl locker in der Tasche saß.

Auch ich war als junge Assistentin froh über jede angesetzte OP, weil sie meine Chancen steigen ließ, selbst am Tisch zu stehen. Aber das ging nun doch deutlich zu weit! Gut, dass ich schon gesetzteren Alters bin und es ein junger Kollege war. Wir wissen, dass Krankenhausärzte ihre ganz eigene Autorität haben, aber ich konnte erfolgreich dagegenhalten. Erleichtert verließ mich die junge Dame eine Weile später, und ich

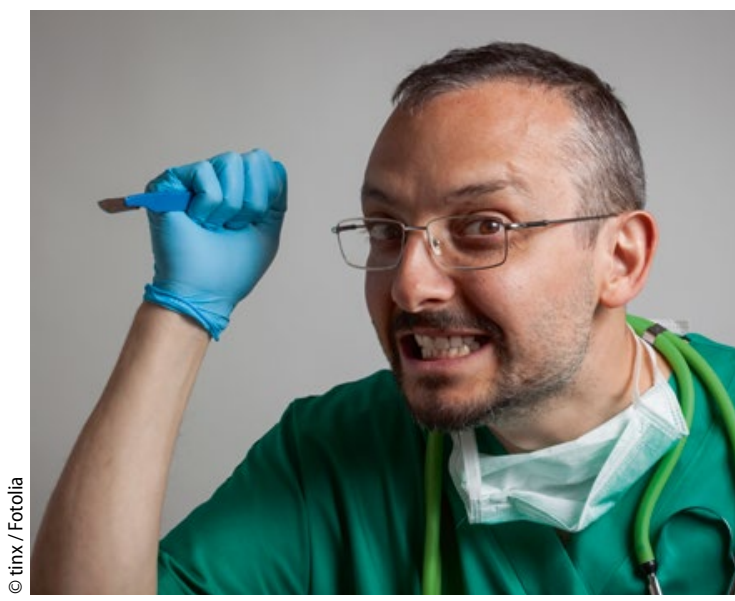

Junge Chirurgen sind froh über jede OP.

überlegte, den Kollegen anzurufen. Aber im gesetzten Alter legt sich Aufregung schnell, und man macht das dann doch nicht. Eigentlich falsch!

Dr. Frauke Höllering, Arnsberg

\section{Die Rentnerbiene wird spontan versorgt}

_ So traurig hatte ich meine Patientin noch nie erlebt. Diese Stimmung passte so gar nicht zu ihr - auch wenn ein Blick aus dem Fenster diesiges Novemberwetter offenbarte. Normalerweise war sie immer beschwingt und fröhlich.

Es war keine großartige Analyse fällig, um den Grund für ihre trübe Laune zu erfahren: Sie erzählte mir, dass sie in eine neue Lebensphase eingetreten war. Sie war jetzt in Rente! Und das bekam ihr weniger gut, als man es vielleicht meinen sollte. Viele meiner anderen $\mathrm{Pa}$ tienten begeben sich in diesem Stadium sofort auf Kreuzfahrt. Schon Monate vorher zählen sie die Tage herunter - the final countdown. Sie aber trauerte ihrer Arbeit nach. Was dem Einen zuviel ist, ist dem Anderen zu wenig.

Da hatte ich eine spontane Eingebung. Seit Monaten schon war ich auf der Suche nach einer "Azubine“, und jetzt dachte ich mir: „Ist doch egal, dann nehme ich eben eine Rentenbiene!"Wie sich herausstellte, war das eine gute Intuition. Dass sie früher schon jahrelang in einer Arztpraxis gearbeitet hatte, hatte ich gar nicht gewusst. Die Einarbeitung war überflüssig, alles lief sofort rund. Das Team hat die neue Mitarbei- terin sofort ins Herz geschlossen. Wie heißt es so schön? Finde, dann musst du nicht suchen! Oder so ähnlich.

Dr. Luise Hess, Darmstadt

\section{Zug spielen}

Sie werden es kaum glauben: Neulich kam ein Lokomotivführer mit einem Infekt zu mir und wollte einen AU-Schein. Beim Betreten des Sprechzimmers klagte er ernsthaft: „Herr Doktor, ich glaube, ich habe mir einen Zug geholt."

Dr. Volker Dietz, Külsheim 